\title{
Talent Management: An Emerging Focus on the Banking Sector of South Africa
}

\author{
Abhinanda $^{1} \&$ Sandeep Muralidharan ${ }^{2}$ \\ ${ }^{1}$ Academic Dean - CTU Training Solutions, Pretoria South Africa \\ ${ }^{2}$ Alumnus, Regenesys Business School - Johannesburg South Africa \\ Correspondence: Abhinanda, Academic Dean - CTU Training Solutions, Pretoria South Africa.
}

$\begin{array}{lc}\text { Received: July 6, 2021 } & \text { Accepted: October 14, } 2021 \quad \text { Available online: October 26, } 2021 \\ \text { doi:10.11114/aef.v8i6.4925 } & \text { URL: https://doi.org/10.11114/aef.v8i6.4925 }\end{array}$

\begin{abstract}
An organisation's talent management practice is a human resource strategy aimed at identifying, developing, deploying and retaining talented and high-potential staff. Talent management is primarily among the human resource practices of employee development. By identifying and enhancing the skills of employees, it not only increases their efficiency, but also results in higher job satisfaction, increased motivation, and elevated retention rates of staff.

The purpose of this research was to look into the impact of talent management on South Africa's banking sector, with reference to the retention of employees. Those included in the study were randomly selected managers and staff from FNB, ABSA and Nedbank. The study's goal was to investigate if targeted talent management influences the retention of employees within the organisation.

This study used a descriptive research design. To obtain quantitative data, the researcher applied a questionnaire. Descriptive statistics were used to analyse the quantitative data produced from Cronbach alpha, Z-test and Chi-square tests. The research disclosed that the primary talent methods are motivation, regular training and employee development.

However, succession planning, career mentoring, recruitment, and selection - as talent management techniques have a direct relationship with employee retention. Based on the study's findings, it is recommended that the organisation should develop effective talent management practices aimed at increasing the retention of employees.
\end{abstract}

Keywords: banking, South Africa, talent management, employee retention

\section{Introduction}

The human resource department in an organisation is transforming, as business faces complex challenges and exploits opportunities. The transformation of human resources today, is due to the rapid changes within business, because of factors - such as globalisation and digitisation.

The new global world has widened the talent pool for outstanding and marginal employees. An organisation's talent can be a source of sustained competitive advantage and can affect important organisational outcomes - such as profitability, survival, customer satisfaction level and employee performance (Kapoor, 2013).

Talent management has grown over the past decade, into a concept of people management, covering the full spectrum from the point of entry of employees into the organisation to their point of exit. Talent management is the proactive design and implementation of an integrated talent-driven organisational strategy to attract, deploy, develop, retain and optimise the appropriate talent requirements, as identified in the workforce plan to ensure a sustainable organization.

South African organisations are currently experiencing economic instability and the drive for talent may be diminishing, as organisations take cost-cutting actions. At the same time, the drive for sustainability is high (McLean, 2016).

\subsection{Background of the Study}

Companies worldwide are encountering global talent challenges in today's fast-moving, extremely uncertain and highly competitive global environment. Among the many factors that shape companies' specific challenges and responses are globalisation, changing demographics, and the demand of workers with necessary skills and motivation and supply of necessary skills and motivation (Kapoor, 2013). 
There are number of factors driving the increasing prevalence of globalisation - including a lack of talent in developed countries, a slow technological progress, growing consumers and the easy availability of low-cost labour in developing countries. Multinational companies need skilled labourers from developing countries at a low cost and therefore the demand of such workers is very high.

Managing such a diverse pool of talent is one of the biggest challenges for a global organisation's human resource department. Due to increasing globalisation, multinational companies need to learn how to integrate a diverse value system and share common global work values, to create an environment in which workers can communicate and coordinate their activities to achieve common goals.

To achieve this - an organisation must practice proper talent management. The need for proper talent and its management is always a difficult task, as it involves recognising the potential stars today and ensuring that they live up to expectations. (Ntonga, 2007).

From a South African point of view, the relevance of talent management is that employees who are considered exceptional performers can benefit from being provided with tools and processes for learning, growing and staying engaged with their current employers and have the opportunity to be proactive in shaping their careers with the organisations. South African companies hold onto the above-mentioned talent management practices, so they can develop their most valued employees and become increasingly dependent on their ability to manage their talent pool effectively (Walker, 2010).

\section{Literature Review}

\subsection{Talent Management Practices}

The connection between outstanding talent management practice and employee retention is increasingly demonstrated by empirical evidence.

Talent management recognizes that various individuals have varied but complimentary contributions that make a company successful (Forman, 2005). However, McGarrity (2007) believes that talent management must be compatible with the corporate strategy and define leadership processes, in line with all functional areas, to remain competitive and efficient. There are various talent management practices that are explained below:

\subsubsection{Employee Work Potential}

Vardarlier \& Y (2012) assert that the major goal of talent management is to maximise organisational efficiency. They also state that retaining talent and dedication is critical to the sustainability of company. Proper use of employees' work potential, also known as human resource planning, entails placing the correct number of people, the right type of people, in the right place, at the right time, doing the right activities, and being suitable for attaining the organization's goals. (Bonadio, 2010). It can be said that maintaining top-performing staff through proper utilisation of their work potential, talent growth and hiring the finest applicants is essential to efficient talent management (Deshmukh, 2006).

\subsubsection{Well-defined and Structured Employee Job-Description}

The initial phase in the talent management process, like with any process with a predetermined result - is planning. It entails determining where the gaps are in human capital requirements, generating job descriptions for important roles to help drive sourcing and selection, and developing a workforce plan for recruitment initiatives. The identification of talent is a critical component of multinational corporations' Global Talent Management procedures. Job analysis, or competency analysis, is a necessary input for talent identification. Nonetheless, according to Stevens, (2013), traditional job analysis, which has been a core requirement for many HR functions, appears to be becoming increasingly obsolete (Scullion, 2011). Indeed, the number of current articles regarding job analysis is declining, but adjacent topics - such as competency modelling and work analysis, which describe more generally and developing organisational responsibilities are increasing.

The connection of competency models with corporate strategy and related performance goals may explain their appeal (Sanchez, 2012). The decreasing usefulness of using job analysis data, such as job descriptions, may be due to a move toward recruitment tactics that are guided not by openings - but rather by onboarding talents to fill strategic roles as they arise. As a result, rather than focusing on existing job responsibilities, organisations may search strategically, in terms of their leadership competence profiles, for visionary talents that are well connected, cross-culturally adept, and whose values align with the corporate culture. (Stevens, 2013). Yamaguchi, (2014) states that job analysis can reveal areas for improvement in the workplace, and have a positive impact on talent management, such as objective and talent-focused development. Improper job descriptions that leave employees unsure of their responsibilities and competencies can also lead to legal concerns.

Smith, (2015) gives an example and asserts that - as demonstrated by Hitachi, rigorous talent identification and evaluation may improve global operations. Although talent selection based on set job features may have become an 
unsatisfactory strategy, the use of particular work profiles to generate good matches between persons and occupations would be beneficial to both employees and companies. (Yamaguchi, 2014) A deeper (psychological) understanding of strategic roles from the perspective of an organisation's HR would undoubtedly help to highlight the relevance of personnel management in accomplishing the increasingly complex and global corporate goals. (Becker, 2010).

\subsubsection{Employee Participation in Decision-Making}

People are the firm core of any successful business. Employees are a source of knowledge and ideas, yet this resource is often underutilised. Involving employees in decision-making not only enables them to contribute to an organisation's success, but it also saves the company time and money through higher productivity and less outsourcing (Anderson, 2019).

Participation increases people's sense of authority and dignity, lessening the urge to demonstrate power by opposing management and limiting production. Employee morale is considerably improved - by involving them in choices and policy changes that directly influence their employment, and empowering them to be more autonomous. Employee involvement conveys the idea that worker inclusion and collaboration actually engages representatives in the workplace and creates a fair method, in which a worker association and support share basic leadership and exhibit the beneficial company results (Verma, 2017).

\subsubsection{Scope of Employee Personal and Professional Growth}

According to Hirsh, (2015) there is no value in finding "talent" or "potential" - if the organisation does not know what the individual wants to do, in terms of a career. It is quite risky for organisations to presume they know what individuals want - in terms of careers, without first asking them. The line manager's responsibility is to assist individuals in surfacing their professional objectives and to examine if what they want to achieve, aligns with what the organisation can provide them, in terms of opportunities.

Career goals can be expressed in terms of grade or level (How eager someone is to advance), but also in terms of direction: What type(s) of job are we considering here? A third essential feature of aspiration is timing - When might a job change be desirable? Managers do require HR assistance in understanding what constitutes a good career dialogue. Career talks, in particular, are all about assisting individuals in determining what they might want to accomplish. This makes them less organisation-focused than performance dialogues and more forward-thinking.

According to Associates, (2008), CEO Michael McCallister emphasises the significance of connecting the company's consumption strategy with human resources. He is renowned with developing a growth and development culture. By demonstrating his visible support and commitment, he instils a "talent mindset" throughout the firm. This is a strong belief that the best and brightest will create shareholder value. Many CEOs are active proponents of talent management today, and their leadership teams work to cultivate talent cultures throughout their firms. CEO Jim Skinner of McDonald's, a Hewitt Top Companies for Leaders winner, has made personnel management and leadership development - one of his top three objectives.

\subsubsection{Well-planned Employee Career Path}

Career paths and ladders can be excellent strategic instruments for improving organisational outcomes. They can be used to ensure that an organisation's growth and productivity continue. (Fox, 2010) Aligning employees' career aspirations with the organisation's strategic goals - not only helps the organisation achieve its goals, but it also helps the organisation differentiate itself from labour market competitors. (Grossman, 2015) Managing employee perceptions of professional growth options is critical to increasing employee engagement and loyalty. HR faces a difficulty in not only continuing to give career prospects for employees, but also in providing options for job enhancement and enlargement. Instead of preparing employees for a lifetime of business work, training and development should focus on preparing them for a lifetime of employability (Lollis, 2008).

\subsubsection{Upskilling of Employees}

According to Feldmann, 2018), the process of training current employees' new skills is known as upskilling. Employers want applicants with particular skill sets to fill new jobs, as technology generates new opportunities. Companies can fill available roles while maintaining their present staff by providing learning opportunities for current employees. According to Amy Adkins, (2016), in the report, How Millennials Want to Work and Live, 59 percent of millennials feel opportunities to learn and improve are extremely important - when searching for a job. In comparison, 44 percent of Gen Xers and 41 percent of Baby Boomers feel the same way about these prospects. Millennials place the largest value on this job feature, indicating the greatest gap between what this generation values in a new career, and what other generations value.

When upskilling becomes established in a company's culture, it naturally attracts job candidates, who appreciate the opportunity to learn. When brand ambassadors within the company know that the company will invest in their future, they are more inclined to promote friends and colleagues to available positions. Employee retention, succession planning, 
career pathing are the benefits for employers, to name a few.

\subsubsection{Creativity and Innovation}

According to Jennifer Schramm, (2007), as global competition heats up and technology takes over ordinary employment - creativity and innovation are becoming increasingly crucial. HR plays a critical role in fostering innovation by creating a creative atmosphere, in which new ideas can flourish. Employer policies that promote creativity and innovation may also aid in increasing employee engagement.

While the management practices that support creative and innovative thinking may be less straightforward than managing task-oriented, routine jobs, their use may ultimately turn out to be more rewarding for managers and human resource professionals. This is not only because these practices highlight the importance of effective human capital management as a driver of value, but also because it is constructing an environment.

Where creative skills and abilities grow, there may be higher levels of employee engagement, motivation, and achievement. Apart from gaining a deeper knowledge of the present drivers of innovation, future skill requirements emphasise the financial return on an environment that fosters creativity and innovation. In a collaborative report compiled by Casner-Lotto, (2006), corporate leaders were polled on the growing content and skill areas they deemed "most vital" over the next five years. Creativity and innovation were ranked fourth. Critical thinking and problem-solving, information technology application, teamwork/collaboration, and diversity also relate to innovation and creativity - either as instruments of creativity and innovation or as a situation, that inspires them.

\subsubsection{Strategic Objectives}

Organisations engage in talent management for a variety of reasons. Bethke-Langenegger, (2013) suggests the following strategic objectives for talent management:

Attracting and retaining talented people: To recruit and retain talent from the internal or external labour market businesses must first understand their employees' needs, and then build and promote incentive systems to meet those demands. It used to be a global phenomenon that employers would provide high job security, in exchange for strong performance and engagement. Today, however - job security is extremely limited. Employers, on the other hand - provide possibilities for advancement and employability, in exchange for employee loyalty and involvement (Dries, 2014).

Human capital development: The goal of developing talents in the process of talent management is to qualitatively improve an organisation's human capital. Employees understand that they cannot rely on their employer, at all costs. Development possibilities in a company meet the needs of talent for career chances and advancement (i.e. regarding job security). This, combined with the changing expectations of the younger workforce regarding their employment situation, results in implicit agreements between the employees and the organisation. Talent management, employee development, and career opportunities, are a currency that organisations offer to gain employee engagement and loyalty (Yi, 2010).

Supporting organisational strategy: Organisations benefit from talent management by putting their plan into action. Employees feel valued and show stronger motivation and organisational commitment, when talent management is recognised as part of the overall plan and an organisation-wide talent mind-set is formed (Gandossy, 2004).

\subsubsection{Proper Job Evaluation}

Job evaluation is a method that evaluates distinct tasks and connects them to remuneration (Armstrong, 2011).The job evaluation exercise should result in the description of duties, relationships of authorities, skills required for each job and job-related relevancies that contribute towards achieving the organisational objections (Levine, 2014). Employee job satisfaction is influenced by many factors, which according to Armstrong, (2011) can be controlled or discussed amicably - if the environment is set right at the working place. One of the most important variables is monetary remuneration. This is always available, regardless of how much one enjoys their profession - especially if one is highly qualified, or thought to be suitably qualified for the same. Factors like working conditions, responsibility, effort and most importantly, skill levels should always be considered during any effective job evaluation (Wong, 2013).

\subsubsection{Employee Diversity in the Workplace}

Workforce diversity is a difficult phenomenon to handle in a company. The importance of managing worker diversity as a tool for increasing organisational effectiveness cannot be overstated - especially given the present global shifts. It is argued that firms that value variety will undoubtedly achieve success, and have a future in this volatile global labour market (Bagshaw, 2004).

Previously, worker diversity was not a serious issue in Africa - to the extent that it is now. The notion of diversity management gained popularity, as a result of globalisation and the need for more organisations to expand globally, in order to reach clients all over the world. In corporate, political, and legal circles, diversity has become a "hot " topic. Managing worker diversity, for example, is one of the most difficult and important difficulties confronting modern 
organisations. Demographic characteristics - such as gender, age, were previously associated with team level outcomes (Watson WE, 1993).

Diversity management can provide a competitive edge. Better decision-making, increased creativity and innovation, greater effectiveness in marketing to foreign and local ethnic minority communities, and a more equitable distribution of economic opportunity - are all potential benefits of diversity (Cox T, 1991). The degree to which managers understand diversity and its possible benefits and drawbacks, defines an organisation's approach to diversity management. It is the approach to diversity that determines the actual positive and negative outcomes - not the diversity itself. (Allen R, 2004).

\section{Research Methodology}

\subsection{Research Sample}

A total of ninety-two (92) employees of ABSA, Nedbank and FNB served as the sample size for this research. The respondents included managers and employees (both junior and senior staff). The selected sample size was chosen, due to the limitations of time and cost. Out of 92 questionnaires, only 80 completely filled-in questionnaires were received. The research focuses on the perceived employee effectiveness of talented management practices on employee retention.

\subsection{Sampling Technique}

The stratified random sampling method was used to sample the survey participants from the target population, to guarantee that all categories of staff were represented in the sampling phase. The staff were divided into two strata of managers and employees of ABSA, Nedbank and FNB. Questionnaires were administered to ABSA, Nedbank and FNB managers and employees (both junior and senior staff) over a period of two weeks. This helped in collecting the information. It was useful to understand the talent management practices employed by ABSA, Nedbank and FNB to increase their employee productivity and retention.

\subsection{Research Design}

The Chi square analysis and Z-test was conducted on 60 responses to ensure correlations were done on the questionnaires, where all the variables were complete and relevant.

\subsection{Data Collection Instrument}

Questionnaires were used as the main instrument for the data collection for this research. The questionnaires administered consisted of close-ended questions. The questionnaires were in two different categories - one for managers and the other for employees. The questionnaires served the purpose for this research by generating responses, which are accurately used for the analysis. Questionnaires were analysed individually, which enabled the researcher to elicit responses that reflected the research objectives outlined. The questionnaires were intended to assess if an effective talent management practice is used as a tool for employee retention.

\section{Data Analysis}

\subsection{Inferential Statistics}

Empirical testing includes a measurement of inferences (Zikmund, 2009). Inferential statistics is the use of statistics to extend the results obtained from the exploration. Inferential measurements allow us to achieve inferences from data, which is not likely to be self-evident. The inferential tests integrated into this study are the Chi square test and the Z-test.

\subsection{Reliability and Validity of Data}

This study meets these requirements in that it correctly measures the extent to which retention of employees depends on an organisation's efficient talent management. According to Nunnaly, (1978), Cronbach's alpha is an essential psychometric test used to assess data reliability. The reliability coefficient represents the dependability of the retail formats used to analyse the impact on consumer behaviour. As a result, many statistical tools can be used and tested.

The internal consistency for employees and managers exhibited a significant alpha () value of 0.865 and 0.94 respectively, after the reliability test. The result of the Z-test and the Chi square analysis are shown in Table 4.1. In order to do the Z test and Chi square test, responses of the Likert scale were weighted, according to the following pattern.

Strongly Agree (SA) - 1, Agree (A) - 2, Neither agree nor disagree (NA/ND) -3, Disagree -4 , Strongly Disagree -5 
Table 4.1. Employees responses to the questionnaire

\begin{tabular}{|c|c|c|c|c|c|}
\hline Variables & $\mathbf{S A}$ & $\mathbf{A}$ & NA/ND & D & SD \\
\hline Work Potential & 0 & 17 & 43 & 0 & 0 \\
\hline Sound Job description & 4 & 55 & 1 & 0 & 0 \\
\hline Participation in Decision Making & 1 & 54 & 3 & 2 & 0 \\
\hline Scope of growth & 1 & 54 & 5 & 0 & 0 \\
\hline Well planned career path & 1 & 55 & 2 & 2 & 0 \\
\hline Upskilling/ Reskilling & 3 & 53 & 3 & 1 & 0 \\
\hline Innovation and Creativity & 5 & 54 & 0 & 0 & 1 \\
\hline Aligned Objectives & 2 & 14 & 41 & 2 & 1 \\
\hline Proper Job Evaluation & 1 & 54 & 5 & 0 & 0 \\
\hline Diversity Management & 3 & 18 & 37 & 1 & 1 \\
\hline Total & 21 & 428 & 140 & 8 & 3 \\
\hline Average/Expected & 2.1 & 42.8 & 14 & 0.8 & 0.3 \\
\hline
\end{tabular}

According to Chen, (2019), a "Z-test is a statistical test used to determine whether two population means are different, when the variances are known and the sample size is large. The test statistic is assumed to have a normal distribution, and nuisance parameters such as standard deviation should be known, for an accurate Z-test to be performed".

Table 4.2. Determination of the critical value

\begin{tabular}{|c|c|c|c|c|c|c|}
\hline $\mathbf{X}$ & $\mathbf{f}^{\prime}$ & $\mathbf{F}$ & $\boldsymbol{d}=\boldsymbol{X}-\overline{\boldsymbol{X}}$ & $\mathbf{d}^{\mathbf{2}}$ & $\mathbf{f}^{*} \mathbf{d}^{\mathbf{2}}$ & $\mathbf{f}^{*} \mathbf{X}$ \\
\hline $\mathbf{1}$ & 2.1 & 2 & -2 & 4 & 8 & 2 \\
\hline $\mathbf{2}$ & 42.8 & 43 & -1 & 1 & 43 & 86 \\
\hline $\mathbf{3}$ & 14 & 14 & 0 & 0 & 0 & 42 \\
\hline $\mathbf{4}$ & 0.8 & 1 & 1 & 1 & 1 & 4 \\
\hline $\mathbf{5}$ & 0.3 & 0 & 2 & 4 & 0 & 0 \\
\hline Total & & $\mathbf{6 0}$ & $\mathbf{0}$ & $\sum \mathbf{d}^{\mathbf{2}=10}$ & $\mathbf{5 2}$ & $\mathbf{1 3 4}$ \\
\hline
\end{tabular}

\begin{tabular}{|c|c|}
\hline Employees & \\
\hline$\sigma_{\mathrm{x}}=\sqrt{\sum \mathrm{d}^{2} /(\mathrm{n}-1)}$ & Where $d^{2}=(X-\bar{X})^{2}$ \\
\hline$\sigma \mathrm{x}$ & 0.17 \\
\hline$\mu=\sum \mathrm{f}^{*} \mathrm{X} / \mathrm{n}$ & 2.23 \\
\hline$\overline{Z Z}=(X-\mu) / \sigma_{x}$ & 4.53 \\
\hline
\end{tabular}

$$
\sum \mathrm{f}^{*} \mathrm{~d}^{2}=52 \quad \sum \mathrm{F}^{*} \mathrm{X}=134
$$

Figure 4.3. 1: Z Test

However, the researcher did an in-depth analysis in Table 4.2 to determine whether the overall impact of the talent management practices of banks in South Africa on their employees' retention strategy is significant or not.

According to the calculations above, the results of the Z-test confirm that the null hypothesis is rejected, because the value of $\mathrm{Z}$ lies outside the acceptance region, as shown in Fig. $1, Z=9.5$, which is greater than 1.96 (>1.96). As a result, the alternative hypothesis is accepted. This results in alternate Hypothesis $\mathrm{H} 1$ being established, confirming the below that talent management practices of South African banks have a significant impact on employee retention.

\subsection{Chi Square Test}

"A chi square ( $(2)$ statistic is a test that measures how expectations compare to the actual observed data (or model results). The data used in calculating a chi square statistic must be random, raw, mutually exclusive, drawn from independent variables, and drawn from a large enough sample". (Hayes, 2019)

Table 4.3. Chi Square test Variables 


\begin{tabular}{|l|l|l|l|l|l|l|l|}
\hline Variables & $\begin{array}{l}\text { Strongly } \\
\text { Agree }\end{array}$ & Agree & Neutral & Disagree & $\begin{array}{l}\text { Strongly } \\
\text { disagree }\end{array}$ & $\begin{array}{l}\text { Chi Square } \\
\text { Value }\end{array}$ & $\begin{array}{l}\text { The two tailed P } \\
\text { Value (df=4) }\end{array}$ \\
\hline Work Potential & 2.10 & 15.55 & 60.07 & 0.80 & 0.30 & 78.82 & $\mathbf{0 . 0 0 0 1}$ \\
\hline Sound Job description & 1.72 & 10.63 & 12.07 & 0.80 & 0.30 & 25.52 & $\mathbf{0 . 0 0 0 1}$ \\
\hline $\begin{array}{l}\text { Participation in Decision } \\
\text { Making }\end{array}$ & 0.58 & 8.96 & 8.64 & 1.80 & 0.30 & 20.28 & $\mathbf{0 . 0 0 0 4}$ \\
\hline Scope of growth & 0.58 & 2.93 & 5.79 & 0.80 & 0.30 & 10.39 & $\mathbf{0 . 0 3 4 3}$ \\
\hline Well planned career path & 0.58 & 3.48 & 10.29 & 1.80 & 0.30 & 16.44 & $\mathbf{0 . 0 0 2 5}$ \\
\hline Upskilling/ Reskilling & 0.39 & 2.43 & 8.64 & 0.05 & 0.30 & 11.81 & $\mathbf{0 . 0 1 8 8}$ \\
\hline Innovation and Creativity & 4.00 & 2.93 & 14.00 & 0.80 & 1.63 & 23.37 & $\mathbf{0 . 0 0 0 1}$ \\
\hline Aligned Objectives & 0.00 & 19.38 & 52.07 & 1.80 & 1.63 & 74.89 & $\mathbf{0 . 0 0 0 1}$ \\
\hline Proper Job Evaluation & 0.58 & 2.93 & 5.79 & 0.80 & 0.30 & 10.39 & $\mathbf{0 . 0 3 4 3}$ \\
\hline Diversity and Inclusion & 0.39 & 14.37 & 37.79 & 0.05 & 1.63 & 54.22 & $\mathbf{0 . 0 0 0 1}$ \\
\hline
\end{tabular}

It is clear from the statistical tests conducted that different variables of talent management of Nedbank, Absa and FNB such as Work Potential, Sound Job description, Participation in Decision-Making, Scope of growth, Well-planned career path, Upskilling/ Reskilling, Innovation and Creativity, Aligned Objectives, Proper Job Evaluation and Diversity and Inclusion, create a significant impact in employee retention. Thus, the employees of banks in South Africa may see their organisation as a promising sector to work in, and aspire to continue their services in the same organisation.

\section{Limitations of the Study}

The research has generated an insight into talent management in South Africa's banking industry about the retention of employees, and can help to enhance the present state of talent management. There are five major banks that dominate the banking industry in South Africa. These banks are ABSA, Nedbank, FNB, and Investec. The fact that the survey was carried out only at ABSA, FNB and Nedbank is a significant study limitation, and limits the study to these banking firms. This excludes the other banking firms and staff who had experienced their organisation's talent management system. The second restriction is that time constraints and company requests of the participants may have impacted on the survey. The third restriction is that the study was based in Sandton, Johannesburg, which ruled out inquiry into other regions of South Africa.

\section{Conclusion}

The study evaluated each objective and determined the extent to which the organisation's talent management practises contribute to the retention of employees. In order to achieve organisational goals and objectives, talent management is increasingly becoming an important organisational strategy. This is because, instead of systems and structures, contemporary HR is becoming more focussed on people. The basic principle of talent management is to effectively manage and maintain talent within an organisation, in order to achieve organisational goals.

The study concludes that the effective practice of talent management helps to retain top talent within an organisation. This research attempted to test the significance of the impact of talent management practices of the banking sector of South Africa on employee retention by using a Chi square test and a Z-test. This research also established the significance of 10 variables - namely, work potential, sound job description, participation in decision making, scope of growth, well-planned career path, upskilling/ reskilling, innovation and creativity, aligned objectives, proper job evaluation, and diversity management on employee retention. The variables were constructed to evaluate the significance of talent management in detail. Cronbach alpha of 0.94 was calculated to measure the internal consistency of the variables chosen to conduct the study.

\section{References}

Allen, R. D. G. (2004). Diversity Practices: Learning Responses for Modern Organisation. Development and Learning in Organisations: An International Journal, 13-15. Retrieved from Diversity Practices: Learning Responses for Modern Organisation. https://doi.org/10.1108/14777280410564185

Amy Adkins, B. R. (2016, June 30). Millennials Want Jobs to Be Development Opportunities. Retrieved from https://www.gallup.com/workplace/236438/millennials-jobs-development-opportunities.aspx

Anderson, C. (2019, March 04). The Advantages of Employee Involvement in Decision Making. Retrieved from https://smallbusiness.chron.com/advantages-employee-involvement-decision-making-18264.html\#: :text=Particip ation\%20in\%20the\%20decision\%2Dmaking,sense\%20of\%20teamwork\%20among\%20workers

Armstrong, M. (2011). A handbook of Human resource Management Practices (9th ed.). London: Kogan Page.

Associates, H. (2008). The State of Talent Management: Today's Challenges, Tomorrow's Opportunities. Retrieved from https://www.shrm.org/ResourcesAndTools/hr-topics/organizational-and-employee-development/Documents/hciLib raryPaper_79300.pdf 
Bagshaw, M. (2004). is diversity divisive? Journal of industrial and commercial training, 36(4), 153-157. https://doi.org/10.1108/00197850410542383

Becker, B. E. (2010). SHRM and job design: Narrowing the divide. Journal Of Organizational Behavior, 31(2-3), 379-388. https://doi.org/10.1002/job.640

Bethke-Langenegger, P. (2013). Talent management - A multilevel analysis in a multiactor context. Dissertation at the Faculty of Economics. Business Administration and Information Technology of the University of Zurich.

Bonadio, S. (2010). The Definitive Talent Management Guide. Softscape People Management Group.

Casner-Lotto, J. (2006). Are they really ready to work? Unites States: The Conference Board, Corporate Voices for Working Families. Partnership for 21st Century Skills and Society for Human Resource Management.

Chen, J. (2019). Z test definition. Retrieved September 9, 2019, from https://www.investopedia.com/terms/z/z-test.asp

Cox, T. J. B. (1991). Managing cultural diversity: implications for organizational competitiveness. The Academy of Management Executive. https://doi.org/10.5465/ame.1991.4274465

Deshmukh, D. G. (2006). Talent Management: A Conceptual Framework with Practical Approach. p. 3/16.

Dries, N. F. (2014). Self-perceived employability, organization-rated potential, and the psychological contract. Journal of Managerial Psychology, 29(5), 565-581. https://doi.org/10.1108/JMP-04-2013-0109

Feldmann, J. (2018, October 2). Knowledge Is Power: The Benefits Of Upskilling For Employers and Employees. Retrieved from

https://www.forbes.com/sites/forbeshumanresourcescouncil/2018/10/02/knowledge-is-power-the-benefits-of-upskil ling-for-employers-and-employees/\#6c53362e23c1

Forman, D. (2005). Principles of human capital management. White River, V.T: Human Capital Institute.

Fox, A. (2010, August 18). At Work in 2020. Retrieved from https://blog.shrm.org/trends/at-work-in-2020?_ga=2.213213972.1066987373.1592757028-477587835.1588344115

Gandossy, R. (2004). Talent wars: Out of mind, out of practice. Human Resource Planning, 27(4), 15-19. https://doi.org/10.7748/ns.19.1.27.s38

Grossman, R. J. (2015, May 1). How to Create a Learning Culture. Retrieved from https://www.shrm.org/hr-today/news/hr-magazine/Pages/0515-learning-culture.aspx

Hayes, A. (2019). Chi square statistic definition. Retrieved September 1, 2019, from https://www.investopedia.com/terms/c/chi-square-statistic.asp

Hirsh, W. (2015). HR in a disordered world. IES Perspectives on HR. ISBN: 9781851844531.

Jennifer Schramm, V. (2007). Workplace Exploring the Future of Work. Society of human Resource Management.

Kapoor, B. (2013). Impact of Globalization on Human Resource Management. Fullerton, USA: Cal State University.

Levine, E. (2014). Evaluation of Job Analysis Methods by Experienced Job Analysts. In Social Science Computer Review, 32(5), 628-646.

Lollis, H. (2008, November 1). Be a Steppingstone. Retrieved from https://www.shrm.org/hr-today/news/hr-magazine/Pages/1108tools.aspx

McGarrity, G. (2007). The key to the future of mid-size businesses. In Strategic talent management. Kensington International.

McLean, C. (2016). TALENT MANAGEMENT: past, present and future. sabpp. https://doi.org/10.1002/wilm.10487

Ntonga, S. (2007). The impact of talent management practices on business performance . johannesburg: University of Pretoria.

Nunnaly, J. (1978). Psychometric theory. In McGraw-Hill. Newyork.

Sanchez, J. I. (2012). The Rise and Fall of Job Analysis and the Future of Work Analysis. Annual Review Of Psychology, 63(1), 397-425. https://doi.org/10.1146/annurev-psych-120710-100401

Scullion, H. (2011). Global talent management. Abington: UK: Routledge. https://doi.org/10.4324/9780203865682

Smith, K. J. (2015). Conducting Thorough Job Analyses and Drafting Lawful Job Descriptions. Employment Relations Today (Wiley), 4l(4), 95-99. https://doi.org/10.1002/ert.21479

Stevens, G. W. (2013). A critical review of the science and practice of competency modeling. Human Resource Development Review : HRD Review, 12(1), 86-107. https://doi.org/10.1177/1534484312456690 
Vardarlier, P. Y. V. (2012). The effects of using talent management with performance evaluation system over employee commitment. In 5. ProcediaSocial and Behavioural Sciences (Ed.).

Verma, V. (2017). Employee's Participation in Decision Making Process. International Journal of Research and Scientific Innovation, 119.

Walker, L. A. (2010). banking on a sustainabl future. capetown: university of capetown.

Watson, W. K. K. (1993). Cultural diversity's impact on interaction process and performance: comparing homogeneous and diverse task groups. Academy of Management Journal, 36(3), 590-602. https://doi.org/10.2307/256593

Wong, C. A. (2013). Authentic leadership, performance, and job satisfaction: the mediating role of empowerment. Journal of advanced nursing, 69(4), 947-959. https://doi.org/10.1111/j.1365-2648.2012.06089.x

Yamaguchi, T. (2014). Standardizing HR Practices Around the World. Harvard Business Review, 92(9), 80-81.

Yi, X. R. (2010). Generational differences in China: Career implications. Career Development International, 15(6), 601-620. https://doi.org/10.1108/13620431011084439

Zikmund, W. G. (2009). Business Research Methods (8th ed.). USA: South-Western College Publishing.

\section{Copyrights}

Copyright for this article is retained by the author(s), with first publication rights granted to the journal.

This is an open-access article distributed under the terms and conditions of the Creative Commons Attribution license which permits unrestricted use, distribution, and reproduction in any medium, provided the original work is properly cited. 